\title{
Role of Bovine Bcl2A1 Gene in Staurosporine-Induced Apoptotic Cell Lines
}

\author{
Luu Quang Minh (Corresponding author) \\ National key laboratory of animal cell technology \\ National Institute of Animal Sciences
}

Tel: 84-983-359-986 E-mail: quangminhven@yahoo.com

\begin{abstract}
Vu Chi Cuong
National key laboratory of animal cell technology

National Institute of Animal Sciences
\end{abstract}

\begin{abstract}
Pham Thi Phuong Mai
National key laboratory of animal cell technology

National Institute of Animal Sciences
\end{abstract}

Giang Thi Thanh Nhan

National key laboratory of animal cell technology

National Institute of Animal Sciences

Tran XuanToan

National key laboratory of animal cell technology

National Institute of Animal Sciences

Luong Nhan Tuan

National key laboratory of animal cell technology

National Institute of Animal Sciences 


\title{
Günther M.Keil
}

\begin{abstract}
Friedrich Loeffler Institut, Institute for Molecular Biology
Insel-Riems, Greifswald, Germany
\end{abstract}

\author{
Tran Xuan Hoan \\ National key laboratory of animal cell technology \\ National Institute of Animal Sciences
}

Received: March 1, 2013 Accepted: March 19, 2013

doi:10.5296/jbls.v4i2.3338 URL: http://dx.doi.org/10.5296/jbls.v4i2.3338

\begin{abstract}
$\mathrm{Bcl} 2 \mathrm{~A} 1$ (B-cell lymphoma 2 - related protein A1) is a member of a gene set that plays a critical role in regulating apoptosis of mammalian cells. The family is divided into 2 groups: (1) anti-apoptotic genes Bcl-2, Bcl-xL, Bcl2A1 and (2) pro-apoptotic genes Bid, Bax, Bak. Apoptosis in cells is regulated by a balanced expression of these groups. In this study, the ORF encoding the 175 amino acid bovine Bcl2A1 protein was amplified by reverse transcription polymerase chain reaction (RT-PCR), using specific primers deduced from the bovine Bcl2A1 mRNA sequence (www//ncbi.nlm.nih.org. Acc: AB195549) and which also contained appropriate restriction endonuclease cleavage sites for cloning. The product was then cloned into plasmid pcDNA3 + to construct the eucaryotic expression plasmid pcDNA3.Bcl2A1. Hela, L11, Vero and WSL cell lines were used to investigate apoptosis induced by staurosporine. Monitoring of cellular DNA fragmentation revealed that incubation with staurosporine at a concentration of $2 \mu \mathrm{M}$ results in a sufficient level of apoptosis induction in Hela, L11, WSL cell cultures after 6 hours and in Vero cell cultures after 12 hours. Transfection of these cell lines with pcDNA3.Bcl2A1, using pseudorabies virus Us3 protein kinase (PrVUs3) which prevents staurosporine induced apoptosis by interacting with the pro-apoptotic proteins Bid and $\mathrm{Bad}$ as a control, proved that expression of the bovine $\mathrm{Bcl} 2 \mathrm{~A} 1$ gene blocks staurosporine-induced apoptosis in Hela and L11 cell lines. However, this activity was not observed in WSL and Vero cell cultures.
\end{abstract}

Keywords: Bovine Bcl2A1, Apoptosis, staurosporine, Transfection, DNA fragmentation, RT-PCR

\section{Introduction}

Apoptosis is the normal biological process of programmed cell death that plays an essential role in regulating growth, development and immune responses by 'clearing' redundant or abnormal cells in organisms. It can be induced by viral infection or exogenous stimuli such as 
staurosporine, sorbitol and UV irradiation (Cartier A., 2003a/b). According to Kurschner (1996), apoptosis is associated with serious diseases among which cancer is a disease that is often characterized by too little or no apoptosis. In contrast, in neurodegenerative diseases such as Parkinson or Alzheimer, too much apoptosis in neuronal cells is thought to be part of the pathogenesis. Moreover, apoptosis is also important for normal placental development. During pregnancy, trophoblast cells from the placenta invade the uterine environment to help establish and maintain a successful pregnancy. The combination of apoptosis and cell proliferation is responsible for shaping tissues and organs in developing embryos. For example, apoptosis of cells located in-between the toes allows for their separation (Dash .P, http://www.sgul.ac.uk/depts/immunology/ dash/apoptosis). Studies of Koichi U., 2005 and Matwee C., 2000 and Yang MY., 2002 in cattle indicated association between apoptosis and bovine embryonic developmental stage as well as quality of the embryo. Hence, understanding of apoptosis and its regulation will open new research orientations in treatment of diseases and improvement of techniques relating to in-vitro fertilization.

So far, the molecular mechanism mediating apoptosis regulation has been considered to involve many factors in which apoptotic regulator family B-cell lymphoma 2 (Bcl2) plays a critical role (Choi SS., 1995; Boise LH., 1993). The Bcl2 family of apoptotic regulators is characterized by the presence of $\mathrm{Bcl} 2$ homology $(\mathrm{BH})$ domains and can be subdivided into two groups: anti-apoptotic proteins (Bcl-2, Bcl-xL, Bcl2A1) and pro-apoptotic proteins (Bid, Bax, Bak) (Hagen SB, 2007; Koichi U, 2005; Reed, 2000, Joseph JK, 1997). They are intracellular membrane-associated proteins and most of them are found in the outer membrane of mitochondria, but some locate in nuclear envelope and endoplasmic reticulum membrane. According to published studies, the balance of expression between the two groups is the molecular basis for regulation of apoptosis (Joseph JK., 1997; Hagen SB., 2007). By cloning the bovine Bcl2A1 gene and analyzing the expression of the gene in trophoblastic binucleate cells of bovine placenta, Koichi U. concluded that bovine Bcl2A1 protein is a new candidate for anti-apoptotic maintenance of the binucleate cells that support placental functions throughout gestation in bovines.

To investigate the functions of anti-apoptotic genes, in this study, we aimed to overexpress bovine $\mathrm{Bcl} 2 \mathrm{~A} 1$ gene to analyze in-vitro its role in staurosporine-induced apoptotic mammalian cells.

\section{Materials and Methods}

\subsection{Materials}

Ear tissue samples of Coc and HF cattle kept in the conservation farm, National Institute of Animal Sciences were taken and immediately stored in liquid nitrogen or RNA-later solution for further studies.

Cell lines such as Hela (Human cervix carcinoma) cells, L11 (ovine) cells, WSL (Wild boar lung) cells and Vero (monkey kidney) cells were grown in Dulbecco's modified eagle medium (DMEM) supplemented with 10\% FCS, $2.4 \mathrm{mM}$ L-glutamine, $100 \mathrm{U}$ of penicillin per $\mathrm{ml}$, and $100 \mu \mathrm{g}$ of streptomycin per $\mathrm{ml}$ or in Minimum essential medium (MEM) supplemented with 


\section{Macrothink}

$10 \%$ FCS, $100 \mathrm{U}$ of penicillin per ml, and $100 \mu \mathrm{g}$ of streptomycin per ml. Cell cultures were incubated at $37^{\circ} \mathrm{C}$ in a humidified atmosphere containing $5 \% \mathrm{CO}_{2}$.

\subsection{Methods}

\subsubsection{Primer Design}

The GenBank accession no. AB195549 sequence was used to design the primers flanking the ORF coding for bovine Bcl2A1 gene (Figure 1). The primers contain adaptors (capital letters) with restriction enzyme cleavage sites for cloning. The primers were commercially synthesized (IDT, USA)

Forward primer: 5'- accGCTAGCGAATTCggagaagatgactgacactgagtttg - 3'

Reverse primer: 5'- ggtGCGGCCGCAAGCTTttcagtcagtagtattgcttcag - 3'

\subsubsection{RNA and DNA Isolation}

About $30 \mathrm{mg}$ of bovine ear tissues stored in liquid nitrogen or in RNA-later solution was used to extract total RNA, according to the protocol of the SV Total RNA Isolation System (Promega). Extraction of RNA from cell cultures was performed using the RNeasy Mini Kit (Quiagen).

To analyze DNA fragmentation, whole-cell DNA was isolated using the Qiamp DNA Blood Mini Kit (Quiagen).

\subsubsection{Reverse Transcription-PCR (RT-PCR) and Specific PCR}

To synthesize cDNA from RNA extracted from bovine ear tissues and cell culture, the Goscript Reverse Transcription System (Promega) and Super Scrip II reverse transcriptase (Invitrogen) were used, respectively.

The entire open-reading-frame (ORF) of bovine Bcl2A1 (Figure 1) was amplified by PCR in 1x PCR buffer supplemented with $1.5 \mathrm{mM} \mathrm{MgCl}_{2}, 200 \mu \mathrm{M}$ dNTPs, $1 \mu \mathrm{M}$ primers, $0.5 \mathrm{U}$ GoTag Hot Start Polymerase (Promega) and $15 \mu \mathrm{l}$ cDNA as template. Amplification conditions were: denaturation at $95^{\circ} \mathrm{C}$ for $2 \mathrm{~min} ; 35$ cycles in which each cycle was set at $95^{\circ} \mathrm{C}$ for $30 \mathrm{sec}$, $58^{\circ} \mathrm{C}$ for $45 \mathrm{sec}$ and $72^{\circ} \mathrm{C}$ for $30 \mathrm{sec}$ and a final extension at $72^{\circ} \mathrm{C}$ for $5 \mathrm{~min}$.

\subsubsection{Construction of Expression Vector pcDNA3.Bcl2A1}

The PCR product containing the bovine Bcl2A1ORF and the plasmid vector pcDNA3+ were digested for 1 to $2 \mathrm{~h}$ with $5 \mathrm{U}$ of each EcoRI and NotI (Promega) per $\mu \mathrm{g}$ DNA in the appropriate (1x) buffer according to the manufacturer's instructions. The plasmid DNA fragment was dephosphorylated by incubation at $37^{0} \mathrm{C}$ for $30 \mathrm{~min}$ with 6 to $8 \mathrm{U}$ of calf intestinal phosphatase (CIP, Promega) per $\mu \mathrm{g}$ DNA in the presence of 1x CIP buffer according to the manufacturer's instructions. The reaction was terminated by addition of $300 \mu 1$ of CIP stop buffer and incubated at $65^{\circ} \mathrm{C}$ for $15 \mathrm{~min}$. After isolation of DNA fragments from agarose gels, a molar ratio of 1:3 of dephosphorylated vector and fragment DNA was used for sticky-end ligations Reactions were carried out with $0.1 \mathrm{U}$ T4 DNA ligase (Promega) in $1 \mathrm{x}$ ligation buffer. Ligations were incubated at RT for $3 \mathrm{~h}$ and subsequently at $4^{0} \mathrm{C}$ overnight. The result was controlled by agarose 


\section{MInstitute Macrothink $^{\text {Int }}$}

gel electrophoresis.

\subsubsection{Transformation}

Competent E.coli JM109 cells (Promega) were thawed on ice. 50 to 200 ng ligated DNA and controls were gently mixed with $50 \mu 1 \mathrm{JM} 109$ cells $\left(5 \times 10^{6}\right.$ cells) and incubated on ice for 20 $\min$. The competent cells were then heated at $42^{\circ} \mathrm{C}$ for exact $2 \mathrm{~min}$, subsequently incubated on ice for $5 \mathrm{~min}$ and $200 \mu \mathrm{l}$ of $\mathrm{LB}$ medium containing $10 \mathrm{mM} \mathrm{KCl}$ and $10 \mathrm{mM} \mathrm{MgSO}_{4}$ was added prior to incubation at $37^{\circ} \mathrm{C}$ for $1 \mathrm{~h}$. The transformation mixtures were spreaded on LB agar plates containing $100 \mu \mathrm{g} / \mathrm{ml}$ ampicillin and incubated at $37^{\circ} \mathrm{C}$ overnight.

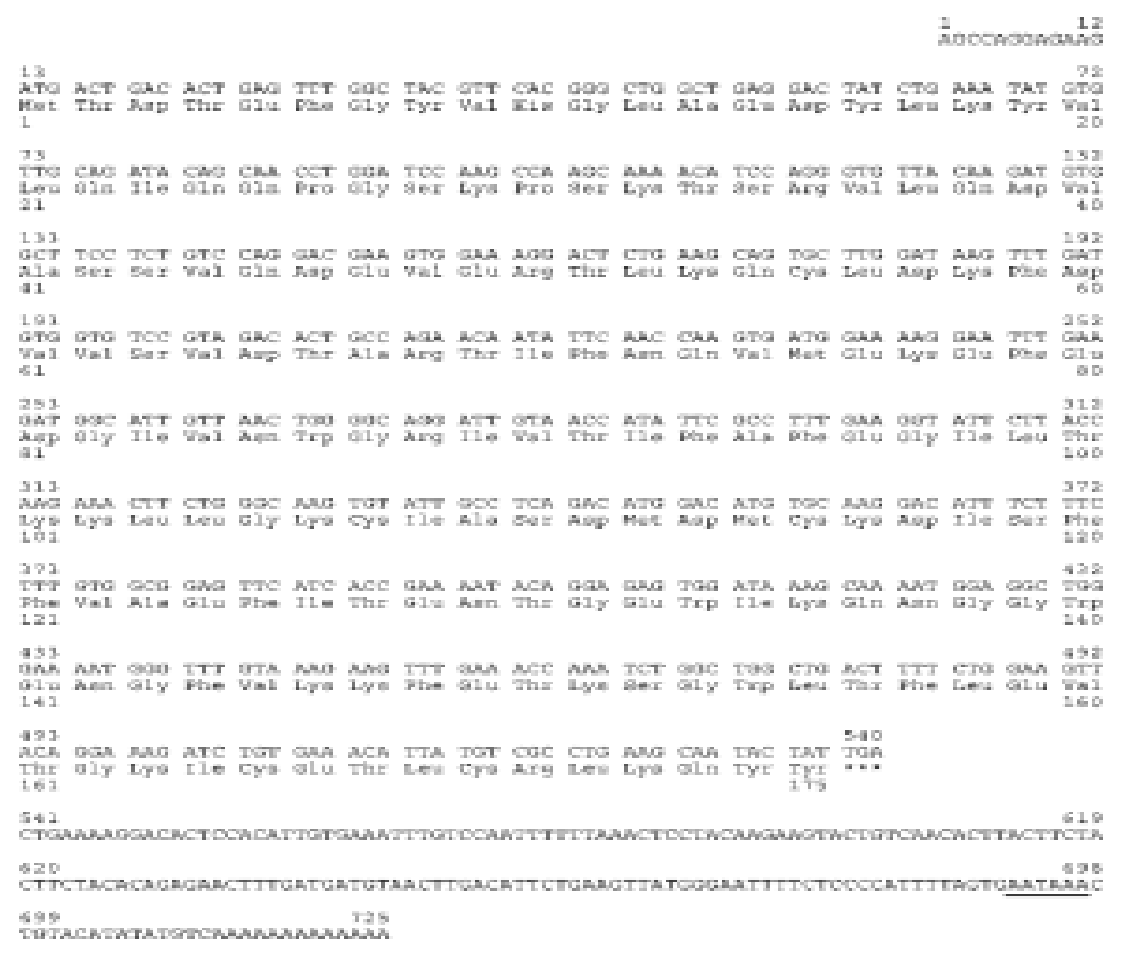

Figure 1. Nucleotide and deduced amino acid sequences of bovine Bcl2A1. The asterisks indicate the termination codon. The polyadenylation signal is underlined.

\subsubsection{Extraction of Plasmid DNA}

The selected colonies were grown at $37^{0} \mathrm{C}$ overnight in LB medium supplemented with 100 $\mu \mathrm{g} / \mathrm{ml}$ ampicillin. Plasmid DNA was extracted, using the PureYield ${ }^{\mathrm{TM}}$ Plasmid Miniprep System (Promega).

\subsubsection{Apoptosis assay}

Apoptosis was induced by the addition of $2 \mu \mathrm{M}$ staurosporine for the respective time, depending on the sensitive level of each cell lines, then followed by DNA laddering assay to detect apoptotic DNA fragmentation

2.2.8 DNA introduction into cells by transfection, using polyethylenimine (PEI)

For transient expression of the Bcl2A1 gene, $2.5 \mu \mathrm{g}$ of plasmid DNA and $5 \mu \mathrm{g}$ of PEI were 
prepared separately in $200 \mu \mathrm{l}$ of serum-and antibiotic-free medium and incubated at RT for 5 min. Subsequently, they were combined, gently mixed and further incubated at RT for $20 \mathrm{~min}$. Confluent cell culture grown overnight in 6-well plates were washed once with $600 \mu \mathrm{l}$ serum-and antibiotic-free medium and the same amount of the medium was added prior to dropwise addition of $400 \mu \mathrm{l}$ sample. The cells were incubated at $37^{\circ} \mathrm{C}$ for $4 \mathrm{~h}$, washed and further incubated in $2 \mathrm{ml} /$ well culture medium containing serum and antibiotics.

\subsubsection{Agarose gel electrophoresis}

To analyze restriction enzyme cleavages, nucleic acid purification, PCR products as well as DNA fragment purification for cloning, agarose gel electrophoresis was used. The agarose gels were prepared at appropriate concentrations and then poured into a horizontal gel apparatus (Biorad). Samples and DNA marker fragments (1 kb ladder (Invitrogen) or smart ladder (Nippongene)) were loaded and the separation was performed at the respective voltage and time, depending on the size of the gel and DNA fragments in 1x running buffer TBE or TAE. Gels were stained in a solution containing $100 \mu \mathrm{g} / \mathrm{ml}$ of ethidium bromide for about $10 \mathrm{~min}$. Documentation of the gel was carried out under UV light.

\subsubsection{Sequencing}

Plasmid DNA or PCR product was sequenced by automated fluorescent DNA sequencing technology (Perkin Elmer, Applied Biosystems). The sequencing reaction was performed using BigDye Terminator Cycle Sequencing Kit and BigDyeXTerminator Purification, according to the manufacturer's instructions. The cleaned products were sequenced by a Genetic Analyzer AB3130 and sequences were analyzed by BioEdit software.

\section{Results and Discussion}

\subsection{RNA Extraction and Bovine Bcl2A1ORF Amplification}

To analyse the quality of the RNA extracted from the bovine ear tissues stored in liquid nitrogen or in RNA-later solution by, RNA was incubated at $70^{\circ} \mathrm{C}$ for 2 min prior to separation on $0.6 \%$ agarose for $30 \mathrm{~min}$ at 100 Volt. The resulting pattern (Figure 2) showed two distinct bands with of about $4.7 \mathrm{~kb}$ and $1.9 \mathrm{~kb}$ specific for $28 \mathrm{~S}$ and $18 \mathrm{~S}$ mammalian ribosomal RNA, respectively, indicating that the RNA remained intact. Since mRNA comprises only 1-3\% of total RNA samples distinct mRNA species are not visible under these conditions.

After reverse transcription of COC and HF cattle RNA the cDNA was used as template in PCR reactions. Figure 3 shows that PCR products of the correct size (572 bp consisting of $528 \mathrm{bp}$ of the bovine Bcl2A1ORF (Figure 1) and 44 bp of adaptor sequences) were amplified.

\subsection{Cloning of Bovine Bcl2A1ORF}

These PCR products were digested with EcoRI and NotI and inserted into plasmid pcDNA3+ cleaved with the same enzymes resulting in expression plasmid pcDNA3.Bcl2A1 in which the transcription of the bovine Bcl2A1ORF is controlled by the human cytomegalovirus (HCMV) immediate early promoter and the bovine growth hormone (BGH) polyadenylation signal sequence. To monitor the cloning process, a PCR was applied directly from a part of colonies 


\section{Macrothink \\ Journal of Biology and Life Science \\ ISSN 2157-6076 2013, Vol. 4, No. 2}

growing on agar plates using the Bcl2A1ORF-specific primer pairs.

The result is shown in Figure 4A and indicated that the 572 bp PCR product of the bovine $\mathrm{Bcl} 2 \mathrm{~A} 1 \mathrm{ORF}$ was amplified only from the plasmids with the Bcl2A1 insertion. This conclusion was confirmed by cleavage of a selected clone and the vector alone with restriction endonuclease HindIII. Since HindIII recognition sites flank the Bcl2A1ORF, two bands with sizes of $5.4 \mathrm{~kb}$ and $528 \mathrm{bp}$ were obtained as expected (Figure 4B). In contrast, only one $5.4 \mathrm{~kb}$ band was present in the HindIII cleaved pcDNA3+.

Sequencing (Figure 4C) of both bovine Bcl2A1ORFs revealed homology of $100 \%$ to the published mRNA sequence (accession number AB195549). Since the sequences of Bcl2A1ORF of Coc cattle and HF cattle were identical, only the Bcl2A1ORF of Coc cattle was used for further studies.

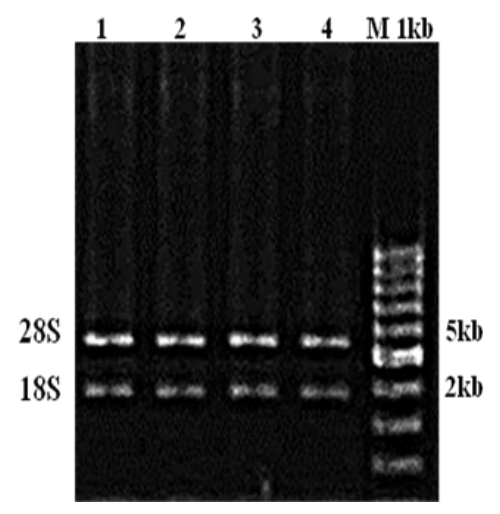

Figure 2. RNA extraction. Ear tissues of Coc and HF cattle stored in liquid nitrogen (1 and 3) and in RNA-later solution (2 and 4) were used for total RNA extraction. Result indicated the presence of two bands $28 \mathrm{~S}$ and $18 \mathrm{~S}$ specific for mammalian RNA molecule

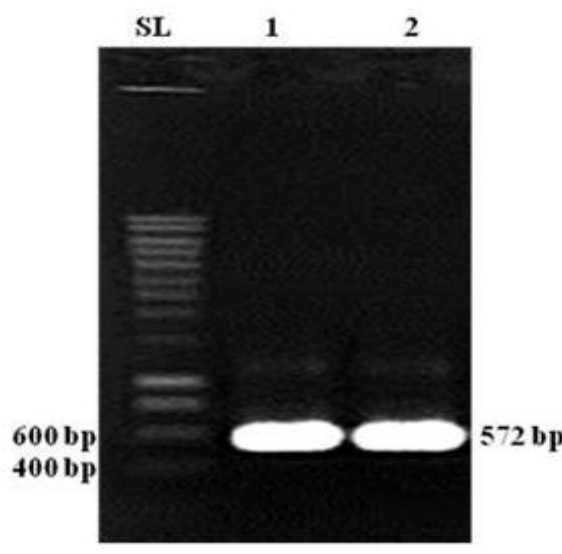

Figure 3. Amplificons of the Bcl2A1ORF from cDNA synthesized from total RNA isolated from Coc cattle (lane 1) and HF cattle (lane 2) ear tissues. DNA was size separated on $2 \%$ agarose gels, stained with ethidium bromide and photographed under UV-light. SL: smart ladder was used 


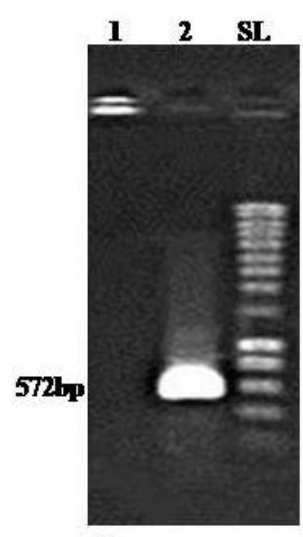

$\mathbf{A}$

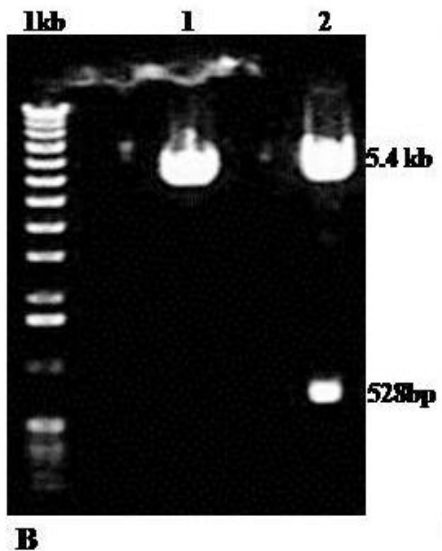

B

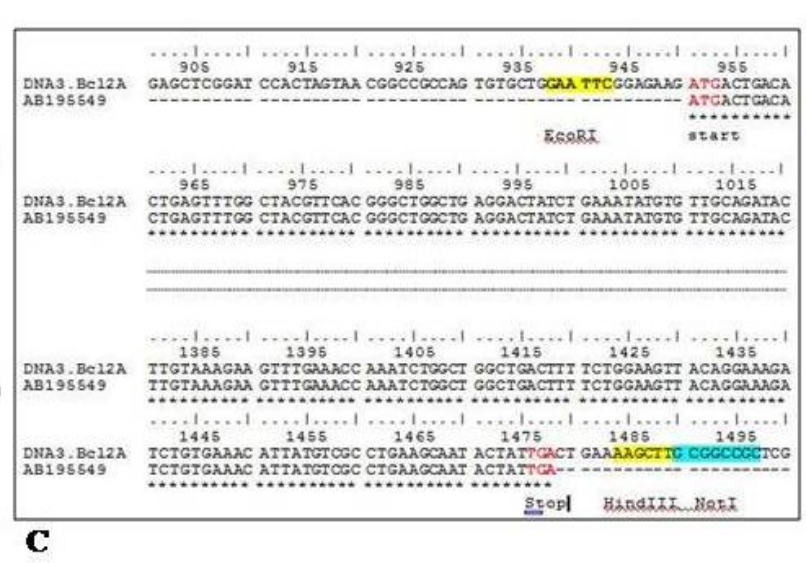

Figure 4. Cloning of bovine Bcl2A1 ORF. (A)-PCR was applied directly from a part of colonies formed by transformation of pcDNA3+ (lane 1) and pcDNA3.Bcl2A1 (lane 2);

(B)-HindIII cleavage of pcDNA3+ (lane 1) and pcDNA3.Bcl2A1 (lane 2); and (C)-Comparision of bovine Bcl2A1 ORF amplified with bovine Bcl2A1 mRNA published (Acc.Nos. AB195549). SL= DNA Smart ladder.

\subsection{Apoptosis induction by Staurosporine}

Staurosporine $\left(\mathrm{C}_{28} \mathrm{H}_{26} \mathrm{~N}_{4} \mathrm{O}_{3}\right)$ is a natural product originally isolated in 1977 from Streptomyces staurosporeus. It is a fungal alkaloid that has for a long time been used in-vitro as an inducer of apoptosis in many different cell lines, but the mechanism involved remains poorly understood (Zhang XD, 2004). Hela, L11, Vero and WSL cell lines were grown in 6-well plates and induction of apoptosis with $2 \mu \mathrm{M}$ staurosporine was monitored in time kinetics. At the indicated times (Figure 5), whole-cell DNA in the cells was isolated and separated on 2\% agarose gels. Analysis of apoptosis induced by staurosporine was done by monitoring cellular DNA fragmentation. The method, as noted by Munger J. (2001), is simple and accurate. The mechanism by which cellular DNA is cleaved during apoptosis induction is briefly outlined as follows: upon receiving specific signals instructing the cells to undergo apoptosis, a number of distinctive changes occur in the cell. A family of cellular proteins known as caspases is typically activated in the early stages of apoptosis. These proteins cleave key cellular components including structural proteins in the cytoskeleton and nuclear proteins such as poly [ADP-ribose] polymerase 1 (PARP-1) that are required for correcting errors in cellular DNA (Boulares AH, 1999). The caspases can also activate other degradative enzymes such as caspase-activated DNases (CAD) that results in DNA degradation by cleavage in internucleosomal regions in apoptotic cells. Figure 5 shows the time kinetics of apoptosis induction, visualized by DNA fragmentation and revealed that DNA laddering is clearly demonstrated after $6 \mathrm{~h}$ incubation of Hela, L11 cells and WSL cells and after $12 \mathrm{~h}$ incubation of Vero cells with $2 \mu \mathrm{M}$ staurosporine. 


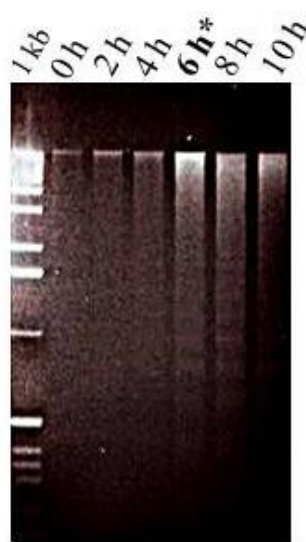

Hela cell

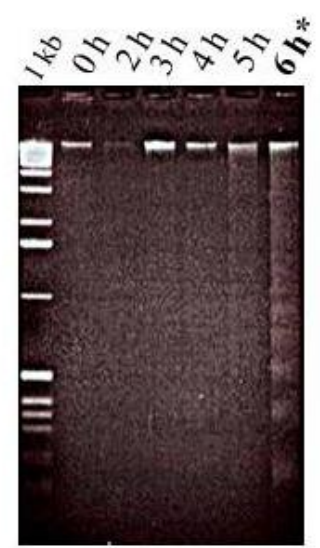

L11 cell

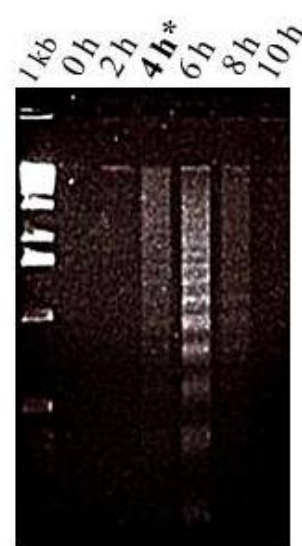

WLs cell

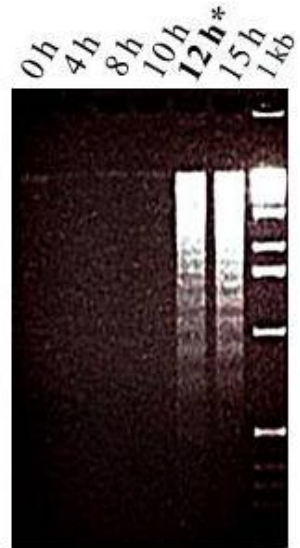

Vero cell

Figure 5. Time kinetics of apoptosis induced by $2 \mu \mathrm{M}$ staurosporine and monitored by DNA fragmentation in Hela, L11, WSL and Vero cell cultures. Whole-cell DNA was extracted at the indicated time points and DNA was size separated on $2 \%$ agarose gels, stained with ethidium bromide and photographed under UV-light.

\subsection{Expression of Bovine Bcl2A1 Gene}

The bovine Bcl2A1 gene was introduced into the cell lines by transfection, using polyethylenimine (PEI). This method uses the cationic polymer polyethylenimine as a carrier, in which the negatively charged DNA binds to the polycation and the complex is taken up by the cell via endocytosis. To determine time and level of Bcl2A1 expression, transfected Hela, L11, WSL and Vero cell cultures were harvested at the indicated time points and wholle-cell RNA was extracted. The resulting RNA was reverse transcribed using oligo (dT) as primer and the Super Script II reverse transcriptase Kit (Invitrogen). The cDNAs were used as templates in PCR reactions with Bcl2A1ORF-specific primers. As shown in Figure 6, specific amplicons with the size of the 528 bp bovine Bcl2A1ORF were observed only when RNA from expression plasmid-transfected cells was used, demonstrating that the bovine Blc2A1 was expressed in all cell cultures at $4 \mathrm{~h}$ post-transfection (p.t). In detail, in Hela and L11 cells, expression of the target gene was strongest at 14 h.p.t whereas the best expression level in WSL and Vero cell cultures was reached later. This result demonstrated that the transfection procedure, resulted in efficient expression of the bovine Bcl2A1 gene all cell lines.

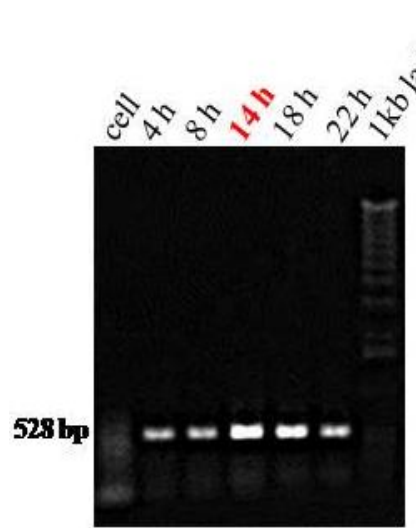

Hela cell
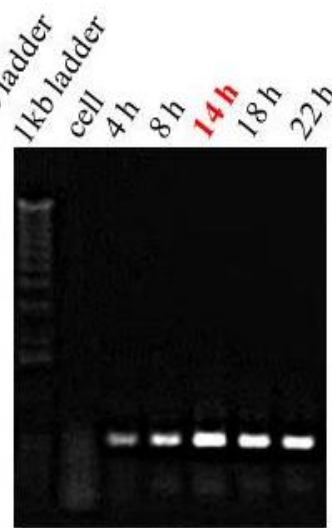

L11 cell

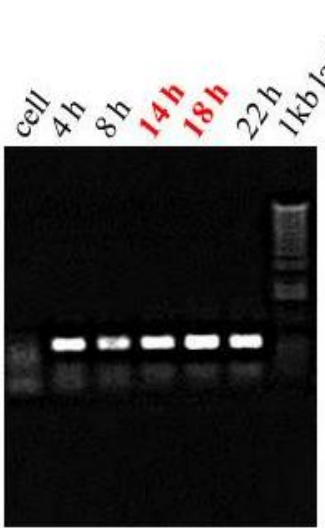

WLS cell

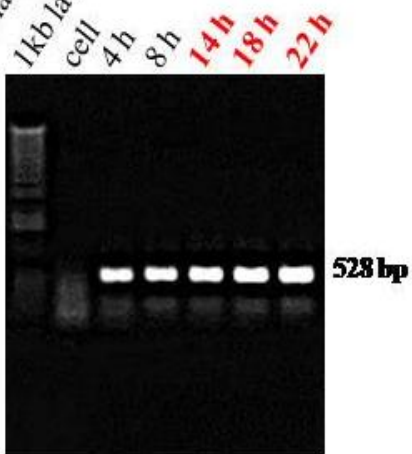

Vero cell 


\section{Al Macrothink}

Journal of Biology and Life Science ISSN 2157-6076 2013, Vol. 4, No. 2

Figure 6. Analysis of expression of bovine Bcl2A1 mRNA. The bovine Bcl2A1 was introduced into the given cell lines by transfection. After the indicated times, transfected cells were harvested for total RNA extraction and then RT-PCR was applied to synthesize cDNA. The cDNA was used as a template in specific PCR to amplify the 528 bp bovine Bcl2A1ORF.

Non-transfected cells were used as negative controls. DNA was size separated on $2 \%$ agarose gels, stained with ethidium bromide and photographed under UV-light.

\subsection{Functions of Bovine Bcl2A1 in Staurosporine-Induced Apoptotic Cell Lines}

To investigate the role of bovine Bcl2A1 in apoptotic cells induced by staurosporine, Hela, L11, WSL and Vero cells were transfected with either pcDNA3.Bcl2A1 or pcDNA3.PrVUs3 (control). At $14 \mathrm{~h}$ post-transfection, the cells were treated with $2 \mu \mathrm{M}$ staurosporine for $6 \mathrm{~h}$ (Hela, L11 and WSL cells) and $12 \mathrm{~h}$ for Vero cell or were left untreated (negative control). Whole-cell DNA was isolated to determine DNA fragmentation. As a control, expression of the pseudorabies virus Us3 protein kinase (PrVUs3) - a protein that prevents apoptosis (Kristin et al., 2005) - was used. Results presented in Figure 7 demonstrated that both PrVUs3 and bovine Bcl2A1 expression partly inhibited staurosporine-induced DNA fragmentation in Hela and L11 cells, providing evidence that bovine Bcl2A1 - like PrVUs3 - blocks apoptosis induced by staurosporine and therefore has anti-apoptotic activity. In contrast, in WSL and Vero cells cultures neither PrVUs3 nor bovine Bcl2A1 expression was capable to inhibit staurosporine-induced DNA fragmentation. The difference of anti-apoptotic function of bovine Bcl2A1 between these cell lines can be attributed to different sensitivities of the cell lines or to the sequence of protein-protein interactions with the cellular target component that Bcl2A1 will probably interact with and thus results in the different effects of bovine Bcl2A1 expression. Kristin et al (2005) showed that PrVUs3 is localized in mitochondria where the majority of apoptotic regulatory proteins reside and their interaction with the Us3 protein inhibits the activities of the pro-apoptotic proteins Bid, Bax. Prevention of pro-apoptotic functions of Bid and Bad by herpes simplex virus Us3 protein kinase (HSVUs3), the functional homolog of PrVUs3 has also been shown (Cartier et al, 2003a/b). Hence, the similarity of anti-apoptotic function between bovine Bcl2A1 and PrVUs3 in Hela and L11 cells leads us to hypothesize that the bovine Bcl2A1 moves to outer membrane of mitochondria where it probably interacts with pro-apoptotic protein(s), resulting in inhibition of apoptosis. This hypothesis is in agreement with studies which show that the balance of expression of anti-apoptotic and pro-apoptotic proteins is essential for regulation of apoptosis in cells (Joseph et al., 1997; Hagen et al., 2007; Koichi et al., 2005). 


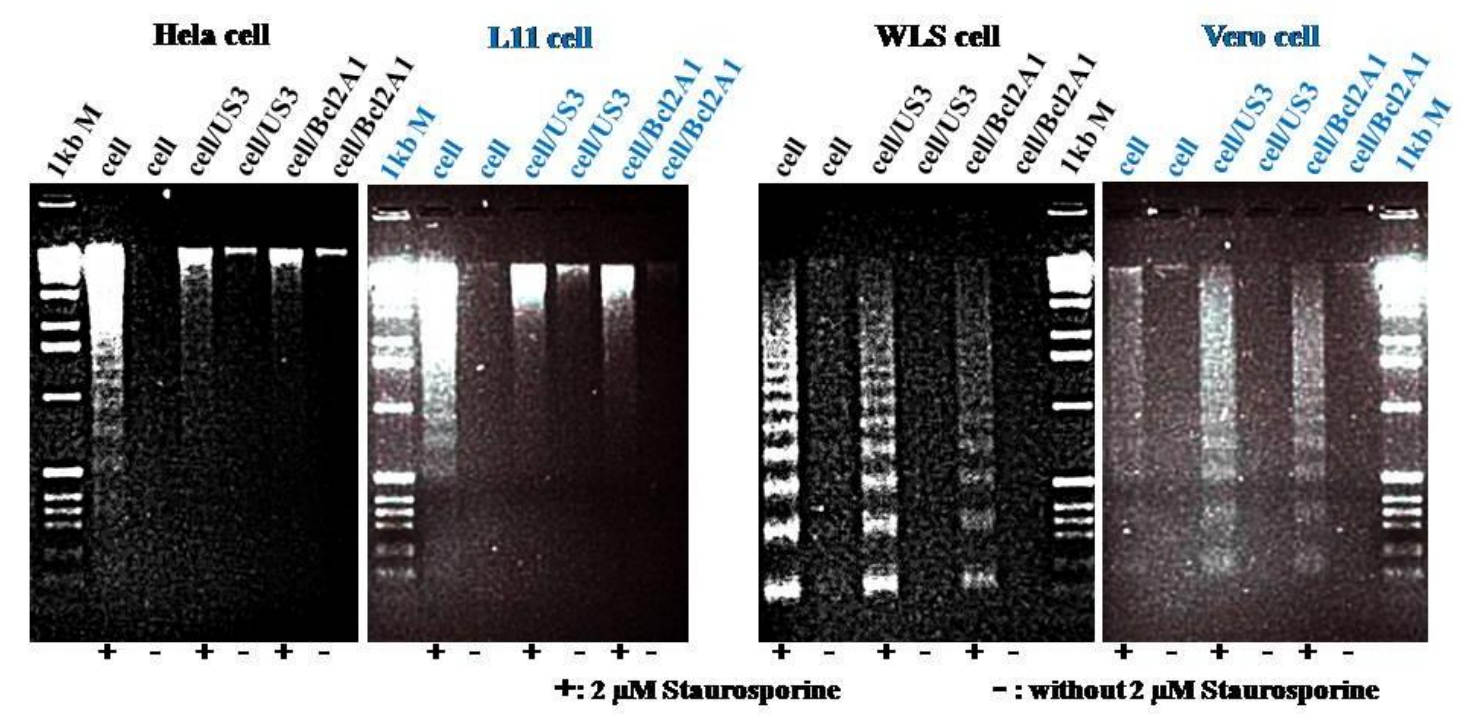

Figure 7. Effect of bovine Bcl2A1 expression in staurosporine-induced apoptotic cell lines. Hela, L11, WSL and Vero cells were transfected with pcDNA3.Bcl2A1 or pcDNA3.PrVUs3

(positive controls) at 14 h.p.t or left non-transfected (negative controls). Apoptosis was induced by incubating the cultures with $2 \mu \mathrm{M}$ staurosporine (+) at the indicated times or left untreated (-). Whole-cell DNA was prepared and analyzed by $2 \%$ agarose gel electrophoresis, stained with ethidium bromide and photographed under UV-light.

\section{Conclusion}

In this study, we have amplified entire ORF of bovine Bcl2A1 gene (528 bp) that deduced 175 amino acids and cloned it into pcDNA3+ to form an expression vector pcDNA3.Bcl2A1. Transfection of mammalian cell lines with the expression vector and then induction of apoptosis by staurosporine demonstrated that the bovine Bc12A1 was well expressed in the cell lines and it played the role as an anti-apoptotic protein in Hela and L11 cells. However, the function was not observed in transfected WSL and Vero cells.

\section{Acknowledgments}

I would like to thank Prof. Dr. Gunther M. Keil of Friedrich Loeffler Institute (Federal Institute of Animal Health), Insel-Riems, Greifswald, Germany for his useful advice and discussion.

\section{References}

Boise LH, Gonzalez-Garcia M, Postema CE, Ding L, Lindsten T, Turka LA, Mao X, Nunez G, \& Thompson CB. (1993). Bcl-x, a bcl-2-related gene that functions as a dominant regulator of apoptotic cell death. Cell, 74, 597-608. http://dx.doi.org/10.1016/0092-8674(93)90508-N

Boulares AH., Yakovlev AG., Ivanova V., Stoica BA., Wang G., Iyer S \& Smulson M. (1999). Role of poly (ADP-ribose) polymerase (PARP) cleavage in apoptosis. The journal of biological chemistry, 274(33), 22932-22940. http://dx.doi.org/10.1074/jbc.274.33.22932

Cartier A., Komai T., \& Masucci MG. (2003). The Us3 protein kinase of herpes simplex virus 1 blocks apoptosis and induces phosporylation of the Bcl-2 family member Bad. Exp Cell Res. 
291(1), 242-250. http://dx.doi.org/10.1016/S0014-4827(03)00375-6

Cartier A., Broberg E., Komai T., Henriksson M \& Masucci MG. (2003b). The herpes simplex virus-1 Us3 protein kinase blocks CD8T cell lysis by preventing the cleavage of Bid by granzyme B. Cell Death and Differentiation, 10, 1320-1328. http://dx.doi.org/10.1038/sj.cdd.4401308

Choi SS, Park IC, Yun JW, Sung YC, Hong SI, \& Shin HS. (1995). A novel Bcl-2 related gene, Bfl-1, is overexpressed in stomach cancer and preferentially expressed in bone marrow. Oncogene,11(9), 1693-1698.

Dash P. Apoptosis. Online available: http://www.sgul.ac.uk/depts/immunology/dash/apoptosis.

Hagen S. Bachmann, Friedrich Otterbach, Rainer Callies, Holger N., Maja Bau Kurt W. Schmid, Winfried Siffert \& Rainer Kimmig. (2007). The AA genotype of the regulatory BCL2 promoter polymorphism $(-938 \mathrm{C}>\mathrm{A})$ is associated with a favourable outcome in lymph node negative invasive breast cancer patients. Clin Cancer Res, 13, 5790-5797. http://dx.doi.org/10.1158/1078-0432.CCR-06-2673

Joseph J Kenny, Thomas J Knobloch, Meena Augustus, Kenneth C Carter, Craig A Rosen \& Jas C Lang. (1997). GRS, a novel member of the Bcl-2 gene family, is highly expressed in multiple cancer cell lines and in normal leukocytes. Oncogene, 14, 997-1001. http://dx.doi.org/10.1038/sj.onc.1200898

Koichi Ushizawa, Toru Takahashi, Kanako Kaneyama, Misa Hosoe \& Kazuyoshi Hashizume. (2005). Cloning of the bovine antiapoptotic regulator, BCL2-related protein A1, and its expression in trophoblastic binucleate cells of bovine placenta1. Biology of reproduction, 74, 344-351. http://dx.doi.org/10.1095/biolreprod.105.042655

Kristin Geenen, Herman W. Favoreel, LeighAnne Olsen, Lynn W. Enquist, \& Hans J. Nauwynck. (2005). The pseudorabies virus US3 protein kinase possesses anti-apoptotic activity that protects cells from apoptosis during infection and after treatment with sorbitol or staurosporine. Virology, 331, 144-150. http://dx.doi.org/10.1016/j.virol.2004.10.027

Kurschner C, \& Morgan JI. (1996). Analysis of interaction sites in homo- and heteromeric complexes containing Bcl-2 family members and the cellular prion protein. Mol Brain Res, 37, 249-258. http://dx.doi.org/10.1016/0169-328X(95)00323-K

Matwee C, Betts DH, \& King WA. (2000). Apoptosis in the early bovine embryo. Zygote, 8(1), 57-68. http://dx.doi.org/10.1017/S0967199400000836

Munger J \& Roizman B. (2001). The US3 protein kinase of herpes simplex virus 1 mediates the posttranslational modification of BAD and prevents BAD-induced programmed cell death in the absence of other viral proteins. PNAS, 98(18), 10410-10415. http://dx.doi.org/10.1073/pnas.181344498

Reed JC. (2000). Mechanisms of apoptosis. Am J Pathol, 157, 1415-1430. http://dx.doi.org/10.1016/S0002-9440(10)64779-7 


\section{Macrothink}

Yang MY, \& Rajamahendran R. (2002). Expression of Bcl-2 and Bax proteins in relation to quality of bovine oocytes and embryos produced in vitro. Anim Reprod Sci. 70(3-4), 159-69. http://dx.doi.org/10.1016/S0378-4320(01)00186-5

Zhang XD., Gillespie SK \& Hersey P. (2004). Staurosporine induces apoptosis of melanoma by both caspase-dependent and -independent apoptotic pathways. Mol Cancer Ther. 3, 187-197.

\section{Copyright Disclaimer}

Copyright reserved by the author(s).

This article is an open-access article distributed under the terms and conditions of the Creative Commons Attribution license (http://creativecommons.org/licenses/by/3.0/). 